\title{
The extent to which math teachers use e-learning innovations and its relationship to their creative thinking.
}

\author{
Rasha Ghani Hashem ${ }^{1}$ \\ Department of Mathematics, College of Education for Pure Sciences, Thi- Qar University, Iraq. \\ corresponding author email: rasha.alfayadh@utq.edu.iq
}

\begin{abstract}
The goal of the research is to know the extent to which math teachers use e-learning innovations and its relationship to their creative thinking. The researcher followed the descriptive approach, and to achieve the objectives of the research ,she designed two research tools, which are a questionnaire included (24) paragraphs, and calculated its sincerity and stability, and the second used the Silver Image Torrance test (a) to measure the skills of creative thinking (flexibility, fluency, authenticity) and then applied to the research sample of (100) mathematician teachers (58 males and 42 females) working in the public schools in Thi Qar province. The results of the survey were properly processed using statistics, and the following results were achieved: the results showed the extent to which e-learning was used in mathematics teaching from the point of view of mathematics teachers, and its overall importance, and the phrases that received the highest percentage of respondents were the phrase (22) [e-learning helps to convey the impact of learning], with a $93.3 \%$ percentage of sample responses on the search tool, while (8) [e-learning helps with the content of continuous learning] has a percentage of the sample responses. The results also showed the positive relationship between the use of e-learning innovations and creative thinking.
\end{abstract}

keywords:

creative thinking, math teachers, e-learning innovations

Article Received: 18 October 2020, Revised: 3 November 2020, Accepted: 24 December 2020

\section{Chapter one}

\section{Research problem}

Most of the world's ambitious and advanced educational systems seek to promote, develop and employ ICT within the educational-learning scientific system, in order to improve the outcomes and quality of the educational process. E-learning in the educational process depends on " interaction either through the Internet or with educational materials through appropriate educational software, and some criticize this type of education as achieving a silent treatment devoid of the vitality of human interaction and social interaction. On the other hand, traditional education and its methods continue to be a major effort among the methods used by the teacher within the classroom, and students are more passive and heavily dependent in their learning to help others" (Al-Hassan, 2013, 3). It is no secret that in an era of cognitive explosion, the burden on educational institutions has increased, "there is an urgent need to use information technology to deliver and address various lessons, including mathematics" (Sayyid, 2002, 5).
The researcher made field visits that allowed her to extrapolate the problem of research through multiple meetings with math teachers. These meetings helped shape the general views of some teachers on the effectiveness of using e-learning innovations in mathematics teaching. Through these various field visits, the researcher established that the views of the teachers differed, some of which were below the desired levels. This prompted the researcher to learn about the extent to which e-learning innovations are used in teaching mathematics and its relationship to their creative thinking. The problem of research is the answer to the following question: How much is the use of elearning innovations in mathematics teaching and its relationship to their creative thinking

\section{The importance of research}

The importance of this research comes from the importance of using e-learning innovations in teaching and the availability of technological competencies in order to employ them from teachers and teachers, as the teacher and teacher 
are the cornerstone of the educational process. The importance of this research comes from:

1. This research may help the designers and authors of the mathematics curriculum to develop the strategies of these curricula, and the methods of teaching them in accordance with e-learning and cognitive explosion, and its advanced techniques.

2. This research may reveal some of the actual constraints that limit the use of e-learning in mathematics teaching.

3. This research may contribute to supporting math teachers and encourage them to use elearning in teaching.

\section{Search goal:}

The current research aims to: identify the extent to which math teachers use e-learning innovations and its relationship to their creative thinking. Search Questions: Current research seeks to answer the following questions

1. To what extent do math teachers use e- . learning innovations in mathematics teaching

2. The relationship between innovations and holistic thinking among mathematics teachers.

Research variables: The researcher assumes both gender and teaching experience independent variables, The views of math teachers in the use of e-learning in the teaching of mathematics are dependent variable.

Time limits: The research tool was applied between 2019/2020

Spatial boundaries: The research was limited to mathematics teachers in public schools in Thi Qar province.

Human boundaries: The current research was limited to a sample of mathematics teachers and public school workers in Thi Qar province.a dependent variable.

Search concepts:

E-learning: "A method of education using modern communication mechanisms from a computer and its networks, its multiple audio and image media, drawings, search mechanisms, electronic libraries, as well as internet portals, whether remote or in the classroom, which is the use of technology of all kinds to communicate information to the learner in the shortest time, less effort and greater benefit" (Musa Mubarak, 2005, 11). The researcher is known procedurally as a kind of modern education that helps the teacher to give sports experiences, and present them in different forms to students using modern technological tools such as computers and its various applications, and the Internet.

Mathematician teacher:

$\mathrm{He}$ is a person with a bachelor's degree and teaches in middle or high schools.

Creative thinking:

Al-Khalili and others (1996) defined it as a "mental activity provoked by a problem or an interesting situation, and it's a jumper who moves its owner from one location to another and from one solution to another without the need to walk routinely, change is its style and goal (Khalil Al

Khalili and others 1996:90).

The researcher defines it procedurally as producing or generating new ideas and finding suitable solutions to the challenges.

\section{Chapter 2}

\section{Theoretical framework}

E- learning:

Digital technology has provided flexible new media in education and previously unknown teaching strategies, emerging new types of education such as open education, virtual and open universities, integrated education and distance learning, and promoting the use of computer-programmed education, $\mathrm{CDs}$ and the Internet, until the recent emergence of the elearning pattern (al kothat,2003).

The concept of e-learning: Abdul Hamid (2005) and Azmi (2008) defined it as "an interactive system of distance learning, provided to the learner according to demand, based on an integrated digital electronic environment, aimed at building courses and connecting them through the internet, guiding and guiding, and organizing

tests".

Al-Ghraib Zaher $(2009,54)$ defined it as "employing a flexible teaching method using technological innovations and internet information 
network equipment, relying on multi-directional communications and providing an educational material that focuses on interactions between learners, faculty, expertise and software anytime, anywhere".

\section{The importance of e-learning:}

Al-Turki (2010) believes that the importance of e-learning can be summarized as follows:

* Interaction between the student and the teacher through the exchange of opinions and educational experiences, discussion, dialogue and knowledge using different channels of communication such as e-mail. (E-Mail) thus increases practical effectiveness. * Its capabilities in providing teachers and students with the necessary skills and competencies through which they can use modern educational techniques.

* Through a variety of new electronic information sources and technologies and expertise, e-learning helps create an interactive learning environment. * E-learning contributes to raising students' higher thinking abilities.

\section{Barriers to the use of e-learning in education:}

Abdul Hafeez (2011) pointed out some of the obstacles to e-learning, the most important of which

are:

Financial problems are the lack of financial * support

Intellectual property issues, fear of loss of privacy.

* Large number of search centers and tools, and the inaccuracy and validity of information available on the internet web sites.

Technical problems of slow and interrupted * communication.

* Students and teachers do not have the technical skills and skills to use ICT in the educational process.

* Fear of students reaching sites with strange ideas about the tolerance of Islam, the customs and traditions of Arab and Muslim societies.

E-learning innovations:
Virtual reality: is one of the technologies that came in technology and prepares the individual the ability to interact with it, and this technique is based on the combination of imagination and reality by finding vivid environments imaginary representing real reality, and can be defined virtual reality as "one of the advanced computer applications that enables the trainee to experience a certain situation is presented in a stereoscopic form of three dimensions as it is in fact through the use of vertical displays associated with the senses of sight, hearing, touch and smell" (Moore et al., 2000)

\section{modern technologies.}

Smart (cellular) phones: Abboud and Ani (2009) pointed out the passage of several decades since the place of mobile phones in actual use in the fields of life and work, its applications in the field of teaching, learning and formulating educational attitudes have positive factors, including:

* Ease of carrying: Using a smartphone and keeping it in the student's bag or pocket without harassment, which makes it a practical device comfortable in carrying for young and old, also makes the smartphone an important device in the formation of educational situations requires this degree of flexibility in communication difficult to form without. * No need for wires: it is a characteristic of its advantage from traditional telephone devices, if the fixed phone is restricted by wires or electrical source, the smartphone has lifted this restriction and increased the flexibility of use and mobility during the operation of the educational situation.

* Digital multimedia transmission: Smartphones lead by transferring text, image and video and delivering them to the beneficiary, and the teacher and his students can exchange data and files in different forms from the method.

* Internet connectivity: I have introduced multiple developments on smartphones to connect to the Internet, which opened up wide areas for its educational uses, where the teacher, student and educational administrative institution, became 
able to benefit from all internet services, and became able to make the smartphone work as a personal computer and fully qualified as a terminal to benefit from the facilities provided by the Internet, which is many in the field of education, learning and in educational management. There are drawbacks of smartphones, including that the limited screen space causes over *ipersdmalefteathesteacher or student who wants to use the smartphone, where it is not being used for long times such as computer, as well as the negatives of health precautions, when excessive use of smartphones have the results tired ness on sight and nervous tension, and the constant feeling of not relaxing, which makes the brain in a state of constant alert.

\section{E-learning in mathematics teaching:}

The National Council of Mathematics Teachers (National Council of Teachers of Mathematics (NCTM) ) was interested in Setting curriculum and evaluation standards in school mathematics (Curriculum and Evaluation Standards for School mathematics) Which focused on the need to upgrade critical thinking skills, solve issues and communicate, reduce reliance on conservation and indoctrination, and invoke rules, formulas or calculations. The use of ICT in mathematics education reinvents mathematics, increases the opportunity to learn it and enhances these skills by integrating ICT into the mathematics curriculum in a good and effective way (Abdul Majid, 2008,

The role and needs of the mathematics teacher in e-learning is different from traditional education .

Zaytoun (2005) points out a number of roles:

* Planning for e-learning.

Choice of educational sites, courses and software.

Works on the evaluation of educational websites,

*software and electronic courses.

Designing educational websites, software and e-

*courses.

Interacts with students in a synchronous, and non-

* synchronous way.

* Provide students with the feedback they need.
* Evaluate teacher's and learner's (Zaytoun, 2005,

79).

According to these roles, there is a need for a minimum teacher to play his or her role in elearning, and some outline the basic qualifications of the e-learning teacher in:

* His understanding of processes in e-learning. * Technical and online communication skills.

* Personal experience and features in the content of study programs (Al-Shahat Awad, 2008, 26).

\section{Thinking}

Thinking is a series of mental activities performed by the human brain when it is exposed to a trigger that is received by one or more of the five senses, and we start thinking when we don't know exactly what to do and think in a broad sense a search for meaning in attitude or experience (Groan, 1999,33). Thinking is described as a form of human behavior, the most complex, and the most important characteristics that distinguish man from other human beings, and this distinction is the result of the structure of the brain and the complexity of the human being compared to its simple composition in animals (Qatami, 2004, 14). Officials have become increasingly sensitive to the value of thinking about the educational aspect, which has led them to invite teachers to practice thinking models that contribute to stimulating students' thinking, understanding their educational experiences, and developing their thinking (Abu Sarhan, 2000, 94). Developing and training teachers to master the thinking skills of students, through the transition to an effective education that requires multiple objectives and the diversity of mental processes and enhance the uniqueness of the individual and self-reliance and excellence of the students, it achieves their mastery of thinking skills and various processes and methods through which they can obtain knowledge and experience themselves (Qatami, Thinking Education, 2001,66).

\section{Creative thinking}

Creative thinking is characterized by the ability to create a beautiful idea, theory, drawing, melody, statue or invention. 
It is clear that the creative work comes only from a creative creationist, with its characteristics and thinking (Abdel Moneim, 24:1995, Ma'ouf Al-

Subai'i, 92:2008).

The production of creative thinking is characterized by unique characteristics that make it enjoy the comprehensive multiplicity of ideas related to the position of "fluency" or improvement and development and expansion "exhalation" or the repeated seriousness of "originality" or the rich diversity of ideas "flexibility". The hope of the nation and those who are able to promote themselves and their communities to the highest degrees of progress and human advancement (Mohammed alBaghdadi, 13:2008). Mamdouh Kanani (2005), believes that creativity is an effective means to reduce the cultural and scientific gap between nations. It is also a critical factor in the progress of societies in each of the areas of human activity (Mamdouh Kanani 15:2005) because it is a sophisticated form of human activity, and helps to achieve self-realization and personal development and in turn helps to form many relationships and ideas (Magdi Ibrahim 260:2005) and provides many alternatives that may contribute to solving the problem and avoid logical sequentiality and the process of differentiation and choice, and the distance from the traditional intellectual style and the modification of attention to a new intellectual path (Amal Al Khalili 138:2005) in knowledge and rapid development and the growth of the basic and social needs of thought to the needs of presenting new ideas atypical, and what the future carries with it the unforeseen possibilities for the human being to face creatively, and address them flexibly and deal with them originally, (Leila Al-

Sa'idi 2007:127).

\section{Previous studies}

Al-Ajlouni and Hamran (2009) conducted a study aimed at identifying the role of ICT in the development of creative thinking among students of the exploratory school in Jordan, and to collect data, the researchers used the Torrance test (images of words) and the study sample consisted of (160) students and Student, (80) students of exploratory schools and (80) students of nonexploratory schools, the results of the study showed that there are statistical differences between the group that learns the usual way and the group that learns using ICT on the overall degree of the Torrance test For creative thinking, and for the benefit of the group that learns using ICT, as well as on the subgrades of the Torrance Test for Creative Thinking, the study showed that there is a real contribution of ICT to the development of creative thinking skills among students.

Study of Al-Sofiani, Maha bint Omar bin Amer

The study aims to identify the importance and use of e-learning in the teaching of mathematics at the secondary level from the point of view of teachers and educational supervisors in public and private schools, and is there a difference between the views of the study sample on the importance and use according to the following variables: variable age, educational level, vocational specialization, years of experience, number of courses enrolled. The study followed the descriptive approach and had a random sample of 160 teachers and 40 supervisors, and the resolution was used as a data

collection tool. The researcher then concluded: * The degree of importance of e-learning in the tasks of the mathematics curriculum at the secondary level from the point of view of the study sample was largely, and the degree of use was moderate.

* The degree of importance of e-learning in the roles of both the female math teacher and the student from the point of view of the study sample

was largely, and the degree of use was moderate. * The degree of importance of e-learning in mathematics development tools from the point of view of the study sample was large, and the degree of use was moderate. * The degree of importance of e-learning and its relevance to analysis from the point of view of the study sample was largely, and the degree of use was moderate.

* There are no statistically significant differences at the level of 0.05 indications between the overall 
averages of the study tool axes depending on the age variable, the educational level, the number of courses in determining the degree of importance and use of e-learning from the point of view of the study sample.

* There are no statistically significant differences at the level of 0.05 indications between the overall averages of the study tool axes according to each career specialization, years of experience in determining the degree of importance and use of e-learning from the point of view of the study sample, while there are statistically significant differences at the level of 0.01 for e-learning in mathematics development tools from the point of view of the study sample.

Al-assaf, Jamal Abdel Fattah Al-Sarayra, Khaled Shaker (2012).

The study aimed to investigate the extent to which teachers are aware of the concept of e-learning, and the reality of using it in teaching in the Second Amman Directorate. The sample of the study consisted of (350) teachers in the Second Amman Education Directorate, selected in a simple random way. In order to answer the questions of the study, a two-pronged questionnaire was developed, the first to look at the extent to which teachers in the Amman Second Directorate of Education are aware of the concept of e-learning, and the second to the reality of using e-learning to teach. The results of the study indicated that there is an above-average degree of awareness among teachers in the Amman Ii Education Directorate of the concept of e-learning on the overall scale of the scale, and on all five sub-dimensions, namely: e-learning features, the role of the school and the learner, the importance of e-learning, the basics of using e-learning, and obstacles in the application of e-learning. She also noted that there were statistically significant differences in the average awareness of teachers about e-learning due to the effect of gender in favour of male teachers. The study also showed a medium degree in computer use, network use, internet use in teachers' e-learning process, as well as statistically significant differences in favour of females in the use of e-learning teachers in teaching. Commenting on previous studies: Some previous studies dealt with the study of the reality of the use of electronic learning and its effectiveness and its importance from the point of view of the advertisers such as the study of Assaf and Sariya (2012), the study of Sifiani (2008), the study of Ajlouni and Hamran (2009), which dealt with the identification of the role of ict in the development of creative thinking, and the study of calligraphy (2013) which aimed to identify the degree to which mathematics teachers use computer in mathematics teaching.

The researcher has benefited from these previous studies in identifying the problem of her research and building the research tool (resolution).

\section{Chapter 3}

Search procedures

Research methodology: According to the objectives and nature of the research, the researcher adopted the descriptive approach to address the problem of this research due to its suitability for the nature of the problem. The descriptive approach is defined as: "The method that is based on the study of the phenomenon, cares about reality, describes the phenomenon accurately and clearly, and expresses it qualitatively or quantitatively" (Obeidat et al., 2004, 203).

\section{Sample search:}

The research tool was distributed to a sample of mathematics teachers in Thi Qar governorate, which were randomly selected, and numbered 100 teachers and teachers of mathematics, 58 males and 42 females.

My research tools:

The aim of the current research is to study the extent to which mathematics teachers use elearning innovations and their relationship to holistic thinking, and to achieve this, two firstidentified tools were built as a major data collection tool distributed to mathematics teachers in public schools in Thi Qar province. The research tools were developed based on a review 
of the theoretical framework, previous studies, and consultation with specialists. The resolution .items were initially made up of 23 lines Creative Thinking Test: The researcher built a test of creative thinking to know the level of creative thinking in the sample members and the researcher followed the following steps which is to rely on the verbal Torrance test for creative thinking, consisting of three skills, namely, flexibility, fluency, and five sub-activities so that each activity takes five minutes except the first and second ten minutes and thus the total time for the application of the test (45) minutes. In addition to benefiting from her experience in her field of mathematics teaching, as well as benefiting from experienced and specialized. The honesty of the research tool: To confirm the apparent honesty of the research tools presented in its initial form to a group of arbitrators, in order to express an opinion and take appropriate observations on the resolution and the measure of test methods. The discriminatory honesty of the study tool was also confirmed, as the two research tools were applied to a simple random sample of sports teachers in Thi Qar province, which reached (27) teachers of mathematics. This type of honesty was verified by a minimum test and a $20 \%$ higher score on this tool, for grades for the honesty and consistency sample. The differences between grades were then calculated by test $(t)$ in order to "ascertain whether the apparent differences between averages are fixed and real, or are caused by accident and sample selection circumstances" (Mikhael, 2011, 122). The results showed statistically significant differences between the highest and lowest scores on this tool. This demonstrates the good discriminatory capacity of the tool, and Table (1) illustrates this:

Table (1)

Shows discriminatory honesty that builds mathematical averages, standard deviations and " $t$ " value.

\begin{tabular}{|c|c|c|c|c|c|c|}
\hline Resolution & $\begin{array}{c}\text { Level of } \\
\text { significance }\end{array}$ & $\begin{array}{c}\text { Value } \\
\text { "t" }\end{array}$ & $\begin{array}{c}\text { Standard } \\
\text { deviation }\end{array}$ & Average & Number & Grades \\
\hline statistically & $\mathbf{0 . 0 0 1}$ & $\mathbf{1 8 . 4 3 3}$ & 4.876 & 156.42 & 27 & $\% 27$ up \\
\cline { 4 - 7 } signified & & 9.281 & 101.16 & 27 & $\% 27$ down \\
\hline
\end{tabular}

It is clear from table 1 that the research tool is sincere, and its provisions have a discriminatory ability to detect the performance of people with higher grades, and those who have obtained minimum grades.

Search tool stability: Using Test-Retest, the stability of the two search tools was calculated. Therefore, the need for a comprehensive approach to the development of the system is a key element in the development of the system. The authenticity and stability of the tool were thus confirmed, making it applicable to the search sample. Statistical methods: The Statistical Package of Social Sciences program was used to conduct statistical packages for Social Sciences (SPSS), value $(t)$ indicative of differences between average scores to compare responses in the case of (sex), as well as discriminatory honesty, pearson and Alpha Kronbach correlation coefficient to calculate correlation and stability coefficient values, and analysis of monovariate (ANOVA) to compare average responses.

Chapter 4

View and interpret search questions:

First: How much mathematics teachers use elearning innovations.

To answer this question, the researcher used the percentages of each paragraph to measure the views of math teachers on the extent to which elearning innovations are used in mathematics teaching. The tripartite scale was adopted (slightly medium-sized). As shown in table 2. 
Table (2)

Shows the percentages of research sample opinions on the extent to which e-learning innovations are used in mathematics teaching

\begin{tabular}{|c|c|c|c|c|}
\hline \multicolumn{3}{|c|}{ Approximation } & \multirow[b]{2}{*}{ Paragraph } & \multirow[b]{2}{*}{ Number } \\
\hline A little bit. & Medium & $\begin{array}{c}\text { To a } \\
\text { large } \\
\text { extent. }\end{array}$ & & \\
\hline$\% 13.3$ & $\% 16.7$ & $\% 70$ & $\begin{array}{l}\text { E-learning is a way of learning using modern } \\
\text { communication tools such as computers and } \\
\text { their multimedia audio, image and graphics. }\end{array}$ & 1 \\
\hline$\% 13.3$ & $\% 16.7$ & $\% 70$ & $\begin{array}{l}\text { E-learning is a way to learn using modern } \\
\text { communication tools such as the Internet in } \\
\text { the classroom. }\end{array}$ & 2 \\
\hline$\% 10$ & $\% 23.3$ & $\% 66.7$ & $\begin{array}{l}\text { E-learning helps increase teachers' capacity } \\
\text { and competence through their use of modern } \\
\text { technological means. }\end{array}$ & 3 \\
\hline$\% 3.3$ & $\% 26.7$ & $\% 70$ & $\begin{array}{l}\text { E-learning helps change the role of teachers } \\
\text { from mentor to mentor and facilitator in the } \\
\text { learning-learning process. }\end{array}$ & 4 \\
\hline$\% 0$ & $\% 36.7$ & $\% 63.3$ & $\begin{array}{l}\text { E-learning helps learners master the skill of } \\
\text { searching, accessing and using information. }\end{array}$ & 5 \\
\hline$\% 23.3$ & $\% 16.7$ & $\% 60$ & $\begin{array}{l}\text { E-learning helps make the outside world } \\
\text { accessible to the student in the classroom. }\end{array}$ & 6 \\
\hline$\% 6.7$ & $\% 33.3$ & $\% 60.0$ & $\begin{array}{l}\text { E-learning makes it easy for students and } \\
\text { teachers to have computer skills and } \\
\text { knowledge in dealing with software. }\end{array}$ & 7 \\
\hline$\% 30$ & $\% 20$ & $\% 50$ & $\begin{array}{l}\text { E-learning constantly updates educational } \\
\text { content. }\end{array}$ & 8 \\
\hline$\% 0$ & $\% 25$ & $\% 75$ & $\begin{array}{l}\text { E-learning makes normal learning more life- } \\
\text { related by using popular and widespread } \\
\text { technological innovations in society such as } \\
\text { the Internet and computers. }\end{array}$ & 9 \\
\hline$\% 0$ & $\% 20$ & $\% 80$ & $\begin{array}{l}\text { E-learning breaks boredom and inertia by } \\
\text { changing the routine of giving lessons. }\end{array}$ & 10 \\
\hline$\% 10$ & $\% 40$ & $\% 50$ & $\begin{array}{l}\text { E-learning helps solve the problem of large } \\
\text { numbers of students. }\end{array}$ & 11 \\
\hline$\% 16.7$ & $\% 33.3$ & $\% 50$ & $\begin{array}{r}\text { E-learning helps transfer knowledge in many } \\
\text { forms. }\end{array}$ & 12 \\
\hline$\% 0$ & $\% 30$ & $\% 70$ & $\begin{array}{l}\text { E-learning helps to take advantage of the } \\
\text { enormous potential of modern technology in } \\
\text { the educational field. }\end{array}$ & 13 \\
\hline$\% 16.7$ & $\% 40$ & $\% 43.3$ & $\begin{array}{l}\text { E-learning helps make education more } \\
\text { flexible. }\end{array}$ & 14 \\
\hline
\end{tabular}




\begin{tabular}{|c|c|c|c|c|}
\hline \multicolumn{3}{|c|}{ Approximation } & \multirow[b]{2}{*}{ Paragraph } & \multirow[b]{2}{*}{ Number } \\
\hline A little bit. & Medium & $\begin{array}{l}\text { To a } \\
\text { large } \\
\text { extent. }\end{array}$ & & \\
\hline$\% 20$ & $\% 23.3$ & $\% 56.7$ & $\begin{array}{l}\text { E-learning helps reduce individual } \\
\text { differences between learners by providing a } \\
\text { variety of learning resources. }\end{array}$ & 15 \\
\hline$\% 10$ & 43.3 & $\% 46.7$ & $\begin{array}{l}\text { E-learning helps increase out-of-class } \\
\text { communication opportunities among } \\
\text { students through electronic media such as e- } \\
\text { mail, social media... }\end{array}$ & 16 \\
\hline$\% 16.7$ & $\% 36.7$ & $\% 46.7$ & $\begin{array}{l}\text { E-learning helps increase opportunities for } \\
\text { communication between students and } \\
\text { teachers outside the classroom through } \\
\text { electronic media such as e-mail, social } \\
\text { media... }\end{array}$ & 17 \\
\hline$\% 6.7$ & $\% 23.3$ & $\% 70$ & $\begin{array}{l}\text { E-learning helps to transform the teaching } \\
\text { method in accordance with students (visual, } \\
\text { audio, visual-audio,...). }\end{array}$ & 18 \\
\hline$\% 6.7$ & $\% 30$ & $\% 63.3$ & $\begin{array}{l}\text { E-learning helps replicate the information } \\
\text {.given to students through multimedia }\end{array}$ & 19 \\
\hline$\% 33.3$ & $\% 50$ & $\% 16.7$ & $\begin{array}{l}\text { E-learning helps make students in a state of } \\
\text { educational stability, so they can get the } \\
\text { information they need at the time they want. }\end{array}$ & 20 \\
\hline$\% 26.7$ & $\% 23.3$ & $\% 50$ & $\begin{array}{l}\text { E-learning helps break down learner's } \\
\text { psychological barriers, promote self-learning } \\
\text { by interacting with other learners and easily } \\
\text { sharing information among them. }\end{array}$ & 21 \\
\hline$\% 0$ & $\% 6.7$ & $\% 93.3$ & $\begin{array}{l}\text { E-learning helps convey the impact of } \\
\text { learning. }\end{array}$ & 22 \\
\hline$\% 26.7$ & $\% 33.3$ & $\% 40$ & $\begin{array}{l}\text { E-learning helps emphasize the objectives of } \\
\text { education in making the learner central to the } \\
\text { educational process through their active } \\
\text { participation in information. }\end{array}$ & 23 \\
\hline
\end{tabular}

It is clear from table 2 that the most high percentage (significantly) was paragraph (22) [elearning helps to convey the impact of learning], the percentage of sample responses was $93.3 \%$ on the scale, followed by paragraph (10) [e-learning breaks boredom and immobility by changing the routine of giving lessons], with $80 \%$ of sample responses on the scale. Followed by phrase (9), with the percentage of sample responses at $75 \%$ on the scale. According to the opinions of mathematics teachers, the percentage of sample responses on the scale was $33.3 \%$, followed by the phrase (8) [e-learning constantly updates educational content.] The percentage of sample responses on the scale was $30 \%$, and their opinions for the rest of the paragraphs varied according to the percentages of their responses on the search tool. The researcher justifies the previous results that mathematics teachers see the importance of e- 
learning in teaching mathematics because it is important to take into account individual differences and strengthen educational content by giving knowledge and skills in different and varied forms.

Second: Is there a relationship between creative thinking and e-learning innovations in mathematics?

The researcher calculated the average grades of teachers on the total score of the creative thinking test and was equal to (22.72), and the standard deviation equals (7.755), where the teacher achieves a degree of creative thinking with a good degree when he gets the score (5.30) and above. The teacher achieves an excellent degree of creative thinking when he gets the mark (37.95) and above. The results showed that the number of teachers who reached the degree of creative thinking has reached the average and above average (58) students, and the percentage (58\%) of teachers and that the number of teachers who reached the degree of creative thinking below the average (20) teachers and the percentage of teachers and $(20 \%)$ of teachers, and the number of teachers who achieved the degree of creative thinking well (12) teachers, and the percentage (12) of teachers. The number of teachers who

Table (3) arithmetic averages and standard deviations of teachers' performance on each skill of the creative thinking test and on the test as a whole.

\begin{tabular}{|r|r|r|c|}
\hline $\begin{array}{l}\text { Total arithmetic average and } \\
\text { standard deviation }\end{array}$ & $\begin{array}{r}\text { Standard } \\
\text { deviation }\end{array}$ & $\begin{array}{r}\text { Average } \\
\text { arithmetic }\end{array}$ & Skill \\
\hline 6.40 & 1.32 & 5.08 & Flexibility \\
\hline 3.139 & 1.46 & 2.93 & Fluency \\
\hline 2.84 & 1.65 & 1.19 & Authenticity \\
\hline 12.263 & 3.143 & 8.120 & $\begin{array}{c}\text { Total degree of creative } \\
\text { thinking skills }\end{array}$ \\
\hline
\end{tabular}

The degree of fluency is 3.139 and more, the degree of flexibility skill 6.40 and more, and the achieved the degree of creative thinking with an excellent degree (10) teachers, and (10\%) of the teachers. That the number of teachers who achieved the degree of creative thinking in general above average (80) teachers, and the percentage $(80 \%)$ of teachers, as determined degree $(75 \%)$ of the total degree to be the degree of cutting or performance acceptable educationally for the ability of creative thinking, and also to know is there a relationship between creative thinking and the innovations of e-learning in mathematics, the researcher calculated the averages and standard deviations of the performance of teachers on the scale in its four dimensions and each activity, calculate the mathematical averages and standard deviations of the performance of teachers on each skill of the creative thinking test and on the test as a whole, and then calculate the limits of the categories to determine the degree of skill achievement where according to the mathematical medium and the standard deviation of each of the four skills. The results indicate a high skill of fluency from the rest of the skills and the convergence of the skill of originality and skill of details of the same level, and the results were according to table 3 . 
Table (4) class boundaries to determine the degree to which teachers achieve skills

\begin{tabular}{|r|r|r|r|r|r|r|}
\hline $\begin{array}{c}\text { Average } \\
+ \\
\begin{array}{c}\text { Standard } \\
\text { deviation }\end{array}\end{array}$ & $\begin{array}{c}\text { Average } \\
+ \\
\text { Standard } \\
\text { deviation }\end{array}$ & $\begin{array}{c}\text { Average } \\
\text { arithmetic }\end{array}$ & $\begin{array}{c}\text { Total } \\
\text { grades }\end{array}$ & $\begin{array}{c}\text { Standard } \\
\text { deviation }\end{array}$ & $\begin{array}{c}\text { Average } \\
\text { arithmetic }\end{array}$ & Dimension \\
\hline 5.9 & 4.4 & 2.8 & 294 & 1.5 & 2.8 & Flexibility \\
\hline 7.9 & 6.6 & 5.2 & 506 & 1.4 & 5.1 & Fluency \\
\hline 3.8 & 2.5 & 1.2 & 117 & 1.3 & 1.2 & Authenticity \\
\hline 17.7 & 13.5 & 9.2 & 917 & 4.2 & 9.1 & Total size grade \\
\hline
\end{tabular}

Also to illustrate the relationship between the innovations of e-learning and creative thinking, the researcher studied each skill individually, dividing the degree of skill into categories, by calculating the mathematical medium and the standard deviation of each skill, while the categories of achievement of teachers achieved skill with an average score and (15) of teachers achieved the skill well and no teacher achieved the skill excellently. Second: Flexibility: that (38) of the teachers achieved the skill with a medium degree and (15) of the teachers achieved the skill well and (3) of the teachers achieved the skill excellently. Third: Originality: That (17) teachers achieved the skill of originality with a medium degree and (11) of teachers achieved the skill well, and (4) of teachers achieved the skill excellently. The teachers achieved the overall score on the three skills in general: (28) of the teachers achieved the skill with an average score, (8) of the teachers achieved the skill well, and (6) of the teachers achieved the skill excellently. The previous results indicate the positive relationship between the innovations of e-learning and creative thinking, and this result is consistent with the result (Rayani 2011) where the study proved the effectiveness of an archaeological program based on some habits of the mind in the development of creative thinking skills and the development of sports power and its processes. Also the study of (Karawi and Sudanese , 2011) confirmed the effectiveness of teaching mental maps in the development of creative thinking, and the study
(Mourning ,2009) showed the effectiveness of the design of a proposed program in calculus based on methods of mathematical thinking in the development of sports creativity and general creativity and the bottom line is that creativity is a form of mental activity practiced by the learner, and all students enjoy a certain inclusion of creativity, although they differ in quantity and not in the type in this characteristic This means the possibility of teaching creativity and training in its practice, and the learner with his mental abilities and positive creative attitudes, he can accept and practice the creative process through the practice of educational teaching activities that expose him to problems that provoke and challenge his mental abilities, and without the availability of these abilities becomes the participation of the learner and his involvement in the creative process is questionable (Ghanem, 2004).

\section{Proposals:}

1. The need to increase the focus during the preparation of teachers on the importance of elearning, and to provide students with teachers with all the related to this type of education. 2. Conduct further research and studies related to the production of educational software, and study its effectiveness in teaching Iraqi mathematics curricula.

3. Legalization of the verbal image (a) of . Torrance tests for creative thinking 4. A comparative study to reveal the effectiveness of electronic innovations in the development of creative thinking skills. 


\section{Recommendations:}

1. Holding training courses and workshops for math teachers to train them in modern e-learning methods.

2. Attention to the development of scientific thinking skills, especially creative thinking skills among teachers and teachers.

3. Conduct other studies dealing with creative thinking skills on other disciplines.

4. Conducting evaluation studies of the programs presented in the scientific sections and their effects in the development of creative thinking.

\section{References:}

[1].Mr. Atef (2002). Educational computer and

*interactive video. Alexandria: Fleming Press [2].Abdel Moneim Haqqi (1995), psychological encyclopedia psychology in our daily lives in education, education, trade, industry, literature, art, war, peace, psychotherapy, home, factory, street, i(1), Cairo, The Library of Madboni [3].Abboud, Harith and Al-Ani, Mezher (2009). (i1). Amman: Wael Publishing House. [4].Abdul Hay, Ramzi (2005). Alexandria: Dar al-Wafa dunya. Abdel-Sama'a, Mustafa and Wahala, Suhair. Teacher preparation: his development and training. Amman, Jordan: House of Thought.

[5].Abdul Majid, Ahmed Sadiq. (2008) A proposed programme in e-learning using open source free software, and its impact on the development of the skills of designing and producing e-math lessons and the trend towards elearning among student teachers. Unpublished research, Curriculum and Teaching Methods [6].Department, Faculty of Education, Sohag, Egypt. [7].Al-Baghdadi, Mohammed Reda (2008), Creative Activities for Children, I(2), Cairo, Arab thought House Al-Jerof, Rima 2001. 13th Scientific Conference: Curricula of Education and The Contemporary Cognitive and Technological Revolution, Egyptian Society of Curricula and Teaching Methods, Volume 1, p. 193-210. [8].Al-Musa, Abdullah al-Mubarak, Ahmed (2005). E-learning: Basics and applications. I1, Riyadh: Data Network Foundation.
[9].Al-Sa'idi, Leila Saad (2007), excellence, talent, creativity and decision-making vision of the reality of the curriculum, i (1), Oman, Dar al-

Hamid

[10].Al-Sofiani, Maha bint Omar bin Amer (2008). The importance and use of e-learning in the teaching of mathematics at the secondary level from the point of view of female teachers and educational supervisors. Master's Thesis, Um alQura University, Faculty of Education, Saudi

Arabia.

[11].Aziz Ibrahim, Magdi (2005), thinking an educational perspective defined by the nature of the skills of developing patterns , i (1), Cairo, the world of books.

[12].Chernoubi, Hashim (2000). The impact of changing examples and analogies in multimedia computer programs on the achievement of independent and cognitively accredited students of multimedia technology concepts, an unpublished master's thesis, faculty of education, al-Azhar

University.

[13].Fathallah, Mohamed Abdel Fattah (2004). The basics of producing and using the means of education technology. Riyadh: Dar al-Sumai. [14].Hindi, Muhammad (2006, Nov. ). The use of a proposed remote training program has affected the awareness of agricultural science teachers of some SOURCES of INFORMATION and Communication Technology. Journal of Studies in Curriculum and Teaching Methods, (118), 225280, Egyptian Society of Curriculum and Teaching Methods. [15].Iman (2003). E-learning is an introduction to non-traditional training. Publications of the Arab Organization for Administrative Development, Cairo.

[16].Kanani Mamdouh, (2005), Psychology of Creativity and Methods of Development, I(1), Amman, Dar al-Marcha. [17].Karawi, The Conclusion and The Sudanese Abdul Karim (2011). The effectiveness of teaching in mental maps in the development of creative thinking among middle-class firstgraders. 
[18].Khalili, Amal (2005), Development of Children's Innovation Capabilities, I (1), Amman

Dar Safaa.

[19].Obeidat et al. Scientific research is its concept, tools and methods. I8, Amman: Dar alFikr. Ajlouni, Khalid and Hamran, Mohammed (2009). The impact of ICT on the development of creative thinking among students of exploratory schools in Jordan. Azmi, Nabil. (2008). Cairo:

Arab Thought House.

[20].Rayani, Ali (2011), Following an archaeological program based on some habits of reason in creative thinking, abilities, athletic strength and operations among middle-class students in Mecca.

[21].The Judges, Khaled (2003), an introduction to the design, production and use of teaching methods and technology. [22].Zaytoun, Hassan Hussein (2005). A new vision in e-learning concept issues application evaluation. Riyadh: Acoustic House of Education. 